\title{
Análise do direito à felicidade de crianças e adolescentes
}

\author{
Analysis to children's and teenagers' right to happiness \\ Análisis del derecho a la felicidad de niños y adolescentes
}

Recebido: 20/04/2021 | Revisado: 26/04/2021 | Aceito: 27/04/2021 | Publicado: 12/05/2021

Sergio Roberto Andrade Martins

ORCID: https://orcid.org/0000-0001-9400-4894 Faculdade Processus, Brasil

E-mail: sergio.andrademartins@ @otmail.com

Jonas Rodrigo Gonçalves

ORCID: https://orcid.org/0000-0003-4106-8071 Universidade Católica de Brasília, Brasil E-mail: professorjonas@gmail.com

Danilo da Costa

ORCID: https://orcid.org/0000-0003-1849-4945 Universidade Católica de Brasília, Brasil E-mail: educadordanilocosta@gmail.com

\begin{abstract}
Resumo
O tema deste artigo é: "Análise do direito à felicidade de criança e do adolescente". Com o problema: "O que caracteriza e como se faz jus ao direito à felicidade de crianças e adolescentes?". Cogitou-se a seguinte hipótese: "os infantes são sujeitos de direitos e deveres, buscando o mínimo básico para serem felizes". O objetivo geral é "fazer uma análise do direito à felicidade da criança e do adolescente"; já o objetivo específico é "colocar em discussão o tema e as leis a elas garantida na busca pela felicidade". Este trabalho é muito importante em uma perspectiva individual para mostrar a vulnerabilidade por afetar a infância e até em situação de risco; para a ciência é uma pesquisa de grade relevância à ciência jurídica; agrega à sociedade por alertar e pelo fato de ter um papel essencial ao chamar atenção à rede de proteção integral. Trata-se de uma pesquisa qualitativa teórica com duração total de quatro meses.
\end{abstract}

Palavras-chave: Felicidade; Direito; Proteção; Integral; Garantia.

\begin{abstract}
The main objective of this essay is: "Analysis of the right to happiness for children and adolescents". With the problem: "What characterizes it and how is the right to joy of children and adolescents is justified?" The following premise was considered "Children are subject to rights and duties, seeking the minimum standard amount to be happy". The overall goal is to "make an analysis of the right to happiness of the child and adolescent"; the specific objectives are: "Putting the topic under discussion and the laws guaranteed to them in the pursuit of happiness." This task is very important in an individual perspective to show the vulnerability to affect childhood and even pupils at risk situation; for science is a very suitable research to the legal science; It adds to society for warning and by having an essential role in drawing attention to the network of full protection. This is a theoretical qualitative research with a total length of four months.
\end{abstract}

Keywords: Happiness; Right; Protectorship; Holistic; Warranty.

\section{Resumen}

El tema de este artículo es: "Análisis del derecho a la felicidad de la niñez y la adolescencia". Con el problema: "¿Qué caracteriza y cómo se vive el derecho a la felicidad de los niños, niñas y adolescentes?" Se consideró la siguiente hipótesis: "Los infantes están sujetos a derechos y deberes, buscando lo mínimo básico para ser felices". El objetivo general es "hacer un análisis del derecho a la felicidad de los niños y adolescentes", mientras que el objetivo específico es "discutir el tema y las leyes que les garantizan en la búsqueda de la felicidad". Este trabajo es muy importante en una perspectiva individual para mostrar la vulnerabilidad por afectar a la niñez e incluso en riesgo; para la ciencia es una investigación de gran relevancia para las ciencias jurídicas; suma a la sociedad por alertar y por tener un rol fundamental en llamar la atención sobre la red de protección integral Es una investigación teórica cualitativa con una duración total de cuatro meses.

Palabras clave: Felicidad; Derecha; Proteccion; Integral; Garantía. 


\section{Introdução}

É imperioso afirmar que a análise do direito à felicidade de criança e do adolescente é o bem jurídico de maior valor dentre os direitos de proteção integral das garantias fundamentais imutáveis da Constituição Federal de 1988 no quesito do Direito da Criança e do Adolescente. Sem o direito das garantias de proteção integral, o direito à felicidade na vida da criança $\mathrm{e}$ do adolescente não subsiste, portanto, é dele que se promove todos os direitos constituindo-se o futuro da nossa sociedade. De tal modo sendo deve ser preliminarmente exigido e tutelado por ser fundamental que deve ser tutelado pelo Estado exercendo de fato o direito absoluto dos menores de 18 anos, contemplados pela Constituição de 1988, sancionado e publicado na Lei ${ }^{\circ}$ 8.069, de 13 de julho de 1990 .

Entre os direitos fundamentais assegurados na Constituição Federal, em relação à criança e ao adolescente e garantidos na Lei no 8.069 - Estatuto da Criança e do Adolescente (ECA) - encontram-se o direito à convivência familiar e o direito à educação, apresentando-se de maneira prioritária à proteção do direito da criança e do adolescente, que visa assegurar em especial atenção do poder público no desenvolvimento de políticas públicas. (Ferreira \& Garms, 2009, p.546).

Este artigo visa ter o propósito de responder ao leitor uma das reflexões apresentadas na pesquisa sobre o tema abordado, no intuito de tentar esclarecer, demonstrar e responder o problema levantado, qual seja: "O que caracteriza e como se fundamenta juridicamente o direito à felicidade de crianças e adolescentes?”. Para que toda criança e adolescente tenha o direito de ser feliz, esta felicidade deve ser alcançada através da contribuição de todos e do poder público por meio de seu poder de tutela dos direitos das crianças e dos adolescentes.

O direito à felicidade não está esboçado em lei, pois este Projeto de Lei ainda não foi sancionado pelo Presidente da República, nem publicado em nenhum Estado da Federação e nem nos Municípios em seu sentido formal, se fazendo valer em direitos expressos previstos em diplomas legais brasileiros, sendo uma realidade que vem engatinhando a passos lentos para proteger direitos das crianças e dos adolescentes, seja por meio da Lei Magna, bem como do Estatuto do Direito das Crianças e dos Adolescentes, tendo muitas vezes que se buscar a tutela jurisdicional na tentativa de resguardar e dar efetividade aos direitos destes. (Souza, Ramos \& Cordeiro, 2018, p.103).

A hipótese diante do problema em debate foi dentro de uma perspectiva de direitos da criança e do adolescente, a felicidade destes pode ser caracterizada em atitudes simples do dia a dia, dando a eles o direito ao mínimo básico para ser feliz, como o direito de brincar, de criar vínculos afetivos, de ser cuidado de forma digna, ser protegido e respeitado em todas as esferas, tendo o direito a se desenvolver de forma saudável e plena. Tanto a criança como o adolescente juridicamente são sujeitos passíveis de direitos e deveres, sendo esses direitos fundamentados juridicamente na Constituição Federal de 1988 e no Estatuto da Criança e do Adolescente, tendo o Estado papel preponderante, assim como a sociedade em geral, do dever de expender medidas de proteção e auxílio, sendo essencial que se desenvolvam em uma família que os ame, ampare, proteja ensinando quais são seus deveres, direitos, regras e limites. Sem nenhuma discriminação, preconceito e sem precisar constrangê-los, dando-se assim aplicabilidade ao princípio da Dignidade da Pessoa Humana para que possa, posteriormente, almejar e poder adquirir a felicidade.

Contudo, esta ligação entre família, sociedade e Estado vem caminhando a passos lentos e não vem apresentando resultados favoráveis e esperados como de fato é necessário. Há muito ainda para que os direitos das crianças e dos adolescentes estejam em patamar de excelência, no sentido de políticas públicas e proteção estatal, tendo ainda um longo caminho a seguir e a ser construído. Desta forma, para que haja uma verdadeira mudança neste cenário real de milhões de crianças e adolescentes, é imprescindível que a sociedade conheça de forma mais completa seus direitos e deveres, assim como as entidades públicas e privadas, se comprometam, de forma efetiva, seu papel de inclusão social, e colocando em prática todas as medidas necessárias à efetivação das políticas voltadas a este fim. (Paschoal \& Marta, 2012, p. 222).

Este artigo tem por objetivo geral fazer uma análise do direito à felicidade da criança e do adolescente em 
contrapartida de políticas governamentais e da parcela de contribuição da sociedade, e de todo ser humano individualmente, quanto a fatores e situações de riscos, e vulnerabilidade que podem comprometer a felicidade de crianças e adolescentes, como seres que fazem parte da sociedade, que merecem ser valorizados, educados com princípios sem discriminação e terem seus direitos preservados, respeitados, e sempre ampliados de forma a dar proteção total, com todo amparo legal. Traz uma abordagem simples e clara do que é preciso para termos crianças e adolescentes felizes em nossa sociedade contemporânea.

Essa temática no âmbito jurídico não possui ainda um conceito formulado de felicidade. Mesmo com muitos estudos científicos ainda paira dúvidas do verdadeiro significado da palavra felicidade. Mesmo assim, é fato que o desejo que todo ser humano, isso envolve também crianças ou adolescente, possuí em seu íntimo é o desejo de ser feliz e busca essa felicidade de modo a tê-la e desfrutá-la com proteção jurídica, mesmo que tal virtude não seja positivada expressamente em nosso ordenamento jurídico pátrio, sendo algo que ainda que caminha a passos lentos, e que se efetivam quase que sempre através de pretensões jurídicas e decisões judiciais. (Souza, Ramos \& Cordeiro, 2018, p.103).

Em relação aos objetivos específicos deste trabalho, o estudo pretende demonstrar ao leitor que muitos são os direitos das crianças e dos adolescentes, mas que estão sendo feridos por falta de políticas públicas, por falta de um olhar mais humanitário da sociedade, e de todo ser humano, bem como tratar dos aspectos e das atitudes positivas que podem trazer a felicidade de crianças e adolescentes em atitudes simples e de verdadeiro engajamento tanto do poder público como de toda sociedade, mostrando caminhos a serem seguidos e o mostrar onde reside a verdadeira felicidade, hoje tão esquecida e tão almejada por nossas crianças e nossos adolescentes, que no futuro se tornarão adultos, e com certeza trará em seu mais profundo íntimo, a vontade de proporcionar a felicidade a esses seres tão vulneráveis. Ainda traz uma abordagem, do papel contributivo da educação e da família na busca pela felicidade das crianças.

A implementação de programas e projetos de estímulo ao desenvolvimento infantil com famílias em situação de vulnerabilidade produz um benefício muito grande para eles e aumenta as oportunidades na vida. Desta forma, fica evidente a importância que deve ser dada a participação estatal e da sociedade na busca dos direitos das crianças e dos adolescentes. Assim, os programas integrados de desenvolvimento infantil podem ser a mais efetiva, eficaz e simples ingerências no sentido de ajudar crianças, famílias, comunidades e nações a exterminar de uma vez por todas esse o ciclo de pobreza intergeracional, que consequentemente gera infelicidade para crianças e adolescentes. (Girade, 2005, p. 9).

Destaca-se a importância do presente estudo sob o prisma de demonstrar a importância do tema para os profissionais do Direito, tendo em vista, o papel preponderante deste profissional, tendo como propósito à proteção e preservação dos direitos da criança e do adolescente, para que possam usufruir do direito fundamental de uma vida digna e consequentemente seja alcançada a felicidade plena.

É de grande relevância a contribuição dada através deste trabalho à ciência jurídica, diante da perspectiva de se trazer uma resposta à problemática: $\mathrm{O}$ que caracteriza e como se fundamenta juridicamente o direito à felicidade de crianças $\mathrm{e}$ adolescentes? E assim, atuar de forma sincronizada com a ciência jurídica, a fim de buscar meios legítimos e legais na proteção da criança e do adolescente, em consonância com os direitos já constituídos legalmente, seja por meio da Constituição Federal de 1988, seja através do Estatuto da Criança e do Adolescente, bem como buscar outros meios de proteção dessa classe tão vulnerável da sociedade e que merece em atenção especial desta ciência em busca do alcance da felicidade.

A sociedade com seu papel fundamental, no que tange à proteção da criança e do adolescente, tem papel preponderante na luta pela conquista de mais direitos, e a pesquisa tem o objetivo precípuo de demonstrar à sociedade que devemos preservar e lutar pela proteção de crianças e adolescentes para que sejam futuramente adultos mais felizes e que possam contribuir de maneira significativa para um país mais justo, mais humano e igualitário para todos, sem discriminação de qualquer tipo. 


\section{Metodologia}

Trata-se de um estudo teórico, com coleta de dados que foram extraídos de artigos científicos, que deram embasamento à pesquisa no âmbito de concentração da pesquisa, com artigos pertinentes ao tema, bem como a utilização de legislação e jurisprudência correlata, no intuito de trazer forma explícita e coerente respostas à problemática levantada.

O instrumento utilizado na pesquisa são artigos científicos, que foram coletados tendo como base o Google Acadêmico, em que foram pesquisados seis artigos e selecionados os cinco artigos que contemplam de forma profunda aspectos importantes, e de importância relevante para estabelecer com o leitor um diálogo profícuo que trará benefícios na busca da felicidade das crianças e do adolescente, em que foi realizada busca através das seguintes palavras-chave: felicidade; direito; proteção; integral; garantia.

$\mathrm{Na}$ busca por material que desse embasamento à pesquisa, foi escolho artigos que tivessem uma abordagem centrada na temática de forma a abranger assuntos desde o direito à felicidade da criança e do adolescente, trazendo à baila a legislação vigente que dá proteção e amparo, bem como a jurisprudência correlata. Neste momento da pesquisa, foi realizada uma seleção do material e sua análise, tendo em vista ser o instrumento base de apoio, foi realizado de forma minuciosa, com escolha de artigos escritos por autor de títulos de doutor ou mestrado e, sucessivamente, feito a escolha levando-se em conta se os artigos científicos foram publicados em revista acadêmica com ISSN.

Importante destacar, de forma temporal cada atividade relacionada à feitura deste trabalho científico como base instrumentaliza dentro de um estudo teórico, que se deu início com a atividade de coleta e análise do material, sendo dispensado um mês, na revisão de literatura, foram dispensados para sua conclusão três meses, e por fim, para a elaboração dos elementos pré-textuais e pós-textuais que compõem todo o trabalho se dando sua conclusão em quatro meses.

O trabalho foi elaborado por meio de uma pesquisa qualitativa com revisão de literatura, e uma análise aprofundada das ideias apresentadas na obra do livro utilizado e nos artigos que deram origem ao trabalho, sendo a metodologia qualitativa, se extraindo a essência e os assuntos mais relevantes para elucidar a problemática proposta, e consolidar ideias para fortalecer direitos e garantias que visem proteger crianças e adolescentes. Um artigo acadêmico, é também considerado um artigo de revisão de literatura que são oriundos de outros artigos acadêmicos ou científicos, ou ainda de livros ou capítulos de livros, que servem de base, ou apoio para fundamentar a temática específica abordada. O artigo de revisão de literatura, é considerado com tal, pois é formado por uma pesquisa de tipologia teórica, ou seja, tem como base obras de autores que tratam do tema abordado. (Gonçalves, 2020, p.97).

\section{Análise do Direito à Felicidade de Crianças e Adolescentes}

Na visão de Ferreira e Garms (2009) e de acordo com a CF/1988 em seu art. 227, é dever da família, da sociedade e do Estado assegurar à criança e ao adolescente, com absoluta prioridade, o direito à vida, à saúde, à alimentação, à educação, ao lazer, à profissionalização, à cultura, à dignidade, ao respeito, à liberdade e à convivência familiar e comunitária, além de colocá-los a salvo de toda forma de negligência, exploração, violência, crueldade e opressão. (Brasil, 1988).

Entre os direitos fundamentais assegurados na Constituição Federal, em relação à criança e ao adolescente e garantidos na Lei $\mathrm{n}^{\circ} 8.069$, Estatuto da Criança e do Adolescente, se encontram o direito à convivência familiar e o direito à educação, apresentando-se de maneira prioritária à proteção da criança e ao adolescente, que visa assegurar em especial atenção do poder público no desenvolvimento de políticas públicas. (Ferreira \& Garms, 2009, p.546).

A família cumpre a função essencial do ser biológico da humanização e os seres humanos por sua vez devem viver em grupos como um ser social, garantindo-se assim a comunicação do patrimônio cultural, costumes e internalizando valores sociais, afetos, padrões e tradições. A família continua sendo a base de uma forma de abordagem geral para o avanço do desenvolvimento social, no processo e no alicerce fundamental para a elevação e a garantias de proteção das crianças, assim 
como o primeiro e em especial o principal veículo a transmitir valores. A família, desta forma, tem um papel fundamental na formação da sociedade. (Salazar, 2008, p. 26-27).

Assim o direito da criança e do adolescente é de extremíssima relevância devido aos direitos assegurados que são prioridade absoluta, relatado pelo artigo 227 da CF/1988, que deu início a partir daí ao passo necessário a criação do Estatuto da Crianças e do Adolescentes, colocando assim a instituição família como a principal tutora e responsável por eles, e, ainda mais, fazendo valer as obrigatoriedades em que cada parte da sociedade se compromete em fazer valer esses direitos adquiridos através do ECA. Assim, segue a leitura dos dois próximos parágrafos, sobre o ponto de vista principal deste artigo em que de fato a criança e o adolescente obterá o direito que lhe é garantido e destacando primordialmente que cada criança e adolescente é sujeito de direitos para ter consagrado o direito de adquirir a felicidade.

Nesse recorrente assunto do cotidiano do ser humano, individual e coletivo, dentro das discussões jurídicas não poderiam ficar afastados, pois o Direito está ligado diretamente às condutas da sociedade. Assim, quem são os protetores da felicidade humana? São várias as áreas da ciência e comunicação humana que questionam e abordam a felicidade que está contida no conhecimento, nas artes, bem como nos projetos de metas pessoais. (Souza, Ramos \& Cordeiro, 2018, p.103).

Segundo Platão, para uma pessoa ser feliz certamente era preciso "fugir do que supunha levar à felicidade". Ao se assemelhar à filosofia socrática, qualificando o nobre idealizador da felicidade como o sujeito numa harmonia de objetivos, descobrindo a verdadeira virtude que é a felicidade, em prática. Nesse sentido, ele acreditava que a felicidade seria a ausência dos excessos, ainda que prazerosos, o pensamento sendo priorizado, assim como o autocontrole e a disciplina. (Leal, 2013, p.15).

Para Sposati (2017), a condução de políticas públicas, como as que ocorre no Programa Criança Feliz (PCF), enfraquece o ECA na proteção integral dos direitos da infância e não se configura como um simples jogo lúdico, mas de decisões astutas que podem desconstruir o ideal de núcleo familiar delineada a partir da CF/1988. No entanto, essa fragmentação pode implicar o desconhecimento da absoluta prioridade para umas faixas etárias da infância. Todavia, o PCF deixa de dar atenção ao princípio da universalidade quando deveria estar disponível para dar total atendimento prioritários ao público, no tocante a política pública, que produz expectativa de direito, porém, na esteira da marcação legal da primeira infância o divisor de corte (zero a seis anos), a definição de "criança" está contida no ECA e desse recorte demarca a primeira infância, de zero a três anos, o que colabora para a segmentação do seio do núcleo familiar, bem além do fato de que não há oferta para o atendimento das crianças e das família em situação de precariedade e vulnerabilidade e nem todos são alcançados. Atua a fragmentação da infância violando o campo normativo. A CF/1988 também constituiu o direito de igualdade e universalidade dentro dos direitos fundamentais, inclusive quando define o direito à educação, a política de assistência social, as doutrinas de proteção integral e o direito à saúde. (Brasil, 1988).

O Programa Criança Feliz infringe o princípio de igualdade e desfaz do conceito de família extensa, assim como as dinâmicas das crianças que se encontram em situação de vulnerabilidade e precariedade. Sendo, assim para Sposati (2017), o PCF destoa dos fundamentos legais que conduz as políticas públicas que buscam dar atendimento às famílias e seus membros da família, foca a figura feminina/mãe como a responsável privilegiada pela criança, e em contrapartida não menciona o instituto da paternidade com responsabilidade. (Sposati, 2017).

A falta de diálogo e confiança entre as diversas áreas das políticas públicas deixa por não concretizar a ideia a que se propõe. Ficando evidente que a não criação de políticas públicas para promover a proteção do desenvolvimento integral de crianças e adolescentes, é ocultado nas múltiplas elaborações normativas que fracionam o seio do núcleo familiar, sem de fato atender realmente as necessidades destas crianças. (Sposati, 2017).

Fica claro que existem programas sociais direcionados para a criança e para o adolescente que não são totalmente benéficos como devem ser de acordo com a garantia fundamental da Constituição de CF/1988, no que diz respeito em ajudar as 
famílias, numa criação de ideal e igualitariedade na formação de seus filhos chegando ao ponto de muitos programas criados para o desenvolvimento das crianças e dos adolescestes, que na verdade não trazem nenhum benefício, sendo até mesmo prejudicial para o núcleo familiar. No que tange aos programas voltados à criança e ao adolescente, é necessário a atenção adequada por parte das autoridades públicas no quesito investimento nas devidas faixas etárias de idade, na formação e no desenvolvimento para uma boa ação na criação dos filhos menores de 18 anos de idade, para de fato atingir o ideal maior, assim como os filósofos defendem e definem a virtude da felicidade, como sugere logo abaixo.

Ainda seria uma "atividade conforme à virtude", conforme dispõe Aristóteles (2003), em sua própria obra Ética a Nicômaco, que sugere que a felicidade seria o bem maior do homem, "uma atividade virtuosa da alma, de certa espécie". Para Aristóteles, a felicidade versaria na prática das virtudes e valores escolhidos desde as antigas civilizações, estando associada à atividade fundamentada nas virtudes e no "bem sumo". (Aristóteles, 2003, p. 29).

Como potência ética apenas aos que puderem pensá-la, quanto algo que se constrói na síntese da vida pessoal como na vida pública é que, estes sim, podem permanecer falando sobre a felicidade. Como conceito dentro de nossas vidas deve-se perguntar antes de ser feliz se pode-se ser ético. Ser feliz será bem mais fácil. A discórdia quanto à felicidade tão-somente mostra que ela está muito mal situada. Hoje em dia, como Kant disse, uns a tratam como algo banal, dizendo que a felicidade é impossível, enquanto outros, como simplesmente realização de bel prazeres. (Tiburi, 2007, p. 51).

Os direitos humanos ao serem positivados trouxeram ao longo da história à condição de sujeito de direitos a elevação da criança, dando atribuição ao Estado, e responsabilizando toda à sociedade e à família na manutenção destes direitos. As transformações bem experimentadas foram inúmeras, especialmente pelos direitos garantidores, quanto aos diplomas regulamentados na garantia fundamental de valores e princípios. (Paschoal \& Marta, 2012, p. 220).

No que pese para o Ministro e médico do Ministério do Desenvolvimento Social e do Desenvolvimento Agrário (MDSA), em posicionamento, a inspiração do PCF é contemporânea, respaldada no que tange o marco legal da primeira infância, na neurociência em estudos e em ações municipais e estaduais. A ênfase da disciplina permanece nas mães, era em grupos de convivência, hoje em dia são abordadas individualmente, em sua própria moradia, por visitantes que ali desenvolvem ativadíssima busca de expressões do materno amor. Nessa preocupação, com as mães em ensiná-las, sob vertente higienista instalada entre os séculos XIX e XX, entre as justificativas do PCF é reproduzida no terceiro milênio (Sposati, 2017).

Cabe certos procedimentos, em tese, a vara da Infância e da Juventude adotados pelo Juiz desta, tidos como especiais, tais como: suspensão e a perda do poder familiar; destituição da tutela; relocando em família substituta; apuração de atos infracionais atribuído ao adolescente; apuração de irregularidades em entidades de atendimento; apuração de infração administrativa às normativas de proteção à criança e ao adolescente. Com total interação do Ministério Público com o Poder Judiciário, com a gratuidade e assistência da justiça e a quem necessitar no maior interesse, bem como garantindo o acesso da criança e do adolescente à justiça. (Sêda, 1992, p. 53).

$\mathrm{Na}$ garantia de fato dos direitos à criança e ao adolescente, pelos ganhos que foram conquistados através dos direitos positivados que trouxe para os dias de hoje, com a obrigatoriedade de toda a sociedade em participar deste avanço social, com empoderamento dos Poderes Público, Judiciário e Legislativo. Nesse interim, toda a sociedade deverá auxiliar para que atinja um só objetivo, que é a realização da felicidade das crianças e adolescentes como sujeito de direito e que não seja só uma felicidade momentânea, como deixa ilustrado nos parágrafos posteriores.

Conquanto tenha indeterminação, há no conceito uma extensão de certeza de caráter negativo - o que realmente não é - e outra no que tange área de certeza de caráter positivo - o que é certamente. Nisso, é imprescindível para apartar aplicações e interpretações incorretas, ainda persista um espaço de incerteza e penumbra. No que tange diante de uma tese jurídico indeterminado, tem-se a possibilidade de domínio jurídico, manuseando sua zona nuclear. (Lamy, 2007, p. 53-54). 
Acrescentando ao que diz o filósofo brasileiro que "a felicidade é episódica, uma ocorrência eventual”. Gilbert (2006) está em conformidade assim como o pensamento de felicidade de Mário Sérgio Cortella, filósofo brasileiro, que discorre a felicidade equiparada a uma "vibração intensa", de alto nivelamento, dando um sentimento de vigor, de plenitude, que atinge toda criatura humana e a deixa com enorme gosto por ter vida. (Sosnowski, 2013).

Num posicionamento de valores sociais do Estado, essa ótica reflete, de forma generalizada, a socialização da criança e o devido cuidado se atribuem à família a responsabilidade exclusiva. Na educação infantil, as creches foram consideradas por longo período como se fosse um mal e era tido como necessário, dentre um meio a se aproveitar em casos extremos de privacidade, na "falta da família" cumprindo assim o seu papel. (Ferreira \& Garms, 2009, p.546).

A família tem naturalização dos cuidados infantis como na sua atribuição exclusiva, ou mais precisamente na figura feminina, ainda parecendo ser um elemento forte inibidor de uma concepção de que essa tarefa possa ser repassada por outros agentes públicos ou em outras esferas sociais. Essa concepção foi assegurada fortemente por teses psicológicas, por um longo período, reforçada por teorias psicológicas assim defendiam vínculos duradouros e a necessidade de um único responsável pela criança, preferível a mãe. (Ferreira \& Garms, 2009, p.546).

Por meio da inserção da criança na família é que esta adquire cultura, valores, e passa a seguir normas de uma sociedade. Para o seu desenvolvimento total e de forma coerente de sua personalidade, a criança deve se desenvolver em um ambiente familiar, envolvida por um sentimento de felicidade, afeto e compreensão (Kaloustian, 2002, p. 7).

Sob esse ponto de vista, para promover uma sociedade qualitativa e mais justa, devemos primeiro promover a instituição familiar sem constrangimento e sem nenhuma espécie de discriminação, para que de fato possa acolher as crianças, e para que não haja o sentimento de falta ou perda. A família é a principal instituição no seio da sociedade que cuida e é a principal responsável para poder operar, cuidar e exigir os reais direitos da infância, garantidos à luz da CF/1988, por conseguinte, pelo ECA.

Contudo, nos direitos da proteção integral, o ECA tem hermeticamente uma metodologia de responsabilidade operativa, ou em outros termos, o como fazer acontecer e por quem. O ECA estabelece, como lei de propositura, que os direitos de fato da criança e do adolescente, confirmados e inerentes do ser humano, apenas declarados não podem ficar. Assim devendo, portanto, integrar o direito pessoal com a concretização do sujeito de direitos, à criança e ao adolescente, com a prioridade absoluta, sem a relativização de seus direitos pela omissão ou pelo desrespeito da ação. (Saut, 2007, p. 61).

Obrigatório que todos, também, possam fiscalizar a efetivação e reivindicar os direitos previstos na Carta Magna de 1988 e no ECA, tais como o direito à vida, à liberdade, à educação e a saúde, entre outros. Todo cidadão, seja membro ou não do Poder Público, possui a prerrogativa e deverá denunciar abusos cometidos por familiares ou por qualquer elemento da sociedade, assim como o dever de colaborar para o crescimento e desenvolvimento social e pessoal dos menores de 18 anos, tratando-os de certa forma inclusiva e com igualdade. (Paschoal \& Marta, 2012, p. 221-222).

Na verdade, a mudança nos referenciais utilizados para a sua definição de infância, veja, o que está ocorrendo com a noção de infância não é seu desaparecimento. Ao debater o histórico da infância, de acordo com o autor, provavelmente uma nova fase está se formando e que as melhores histórias produzidas, além de qualquer coisa, são construídas quando os conceitos estão em baixa. Para Postman (1999), desde não ter uma palavra para defini-la até a descrição detalhada de suas características, muitas foram as etapas que passaram a ideia de infância.

Na sociedade contemporânea a "cultura" infantil ganhou uma nova conotação, com modificações, até mesmo em suas características próprias, como a forma de se vestir, o tipo de alimentação, a forma de linguagem, as brincadeiras realizadas, bem como até os tipos de desenhos animados hoje preferidos. Inegavelmente, esta é a nova realidade, o autor busca demonstrar que estamos diante de uma crise no conceito de infância. (Postman, 1999).

A concepção de criança e adolescência está sempre atrelada a imagem de um adulto e, que tem como resultado, tendo 
em vista que a criança de hoje será o adulto amanhã que foi moldado dentro do recinto familiar, com influência também do contexto em que estes adultos foram inseridos e se desenvolveram, tendo ainda que se falar também na participação da escola na formação das crianças e dos adolescentes. Como resultado de uma evolução da própria sociedade, que estará sempre em movimento e mudanças, e do enfoque dado ao adulto, a vivência da infância também sofrerá alterações a depender dos paradigmas do contexto histórico. (Silveira, 2000).

A forma pela qual o ordenamento jurídico brasileiro vem tratando os valores, no meio da sociedade, para uma convivência digna na infância e na adolescência, vêm sofrendo várias mudanças, desde os princípios até mesmo na efetivação da educação para com o comportamento, poderíamos dizer que de fato estamos diante de uma crise institucional familiar instalada e que se não houvesse a garantia de direito adquirido da criança e do adolescente hoje essa situação seria bem pior, agora por meio dos representantes legais constituído pela sociedade de um modo geral, que desde a criação dos Conselhos Tutelares pela Lei $n^{\circ}$ 8.069/90 e a CF/1988 que instituiu o ECA, e que vem fazendo um trabalho orquestrado através do sistema de rede de proteção adquirido dentro deste período.

Conselho Tutelar, órgão autônomo e municipal, não jurisdicional, que possui função pública estando vinculado à administração pública, tendo autonomia para exercer suas atribuições de forma permanente, com a obrigação dada pela sociedade, de proteger os direitos da criança e do adolescente, não tem função jurisdicional, sua criação trouxe um grande avanço para efetivação do Estatuto da Criança e do Adolescente. (Saut, 2007, p. 63-64).

O Conselho Tutelar entidade administrada de forma Estadual/municipal que deve cuidar pela condição especial da criança e do adolescente, com uma proteção radical dos seus "direitos humanos e da sua dignidade humana, tendo esta defesa amparo no fundamento do Estado Democrático de Direito", modelo do direito político que garante o direito da doutrina da proteção integral e que tem a dignidade humana como princípio norteador da ética. Um órgão que a sociedade escolhe os seus representantes pelo voto para promover o controle social e o interesse da sociedade quando busca a defesa de forma integral dos direitos das crianças e dos adolescentes, e dando prioridade total em todas as situações. O Conselho Tutelar é o estabelecimento, é a voz das crianças, é o defensor e protetor dos direitos da criança e do adolescente. (Machado, 2003, p. 405).

Adolescente, é definido como "quase adulto", já possuidor das noções de ligação e moral, com sua formação quase completa e sendo capaz de diferenciar e identificar atos mais complexos. Ao se pensar em criança, de imediato nos vem à cabeça a figura de um ser de pouquíssima idade, vulnerável e necessitado de cuidados, proteção especial, atenção e acompanhamento psicossocial. (Paschoal \& Marta, 2012, p. 223).

O termo infância tem sua origem no latim in-fans, que significa sem linguagem. Para a filosofia ocidental, não ter linguagem quer dizer não ter pensamento, não ter conhecimento, não ter raciocínio. Assim a criança é definida como um ser pequeno, de pouca formação, que ainda não possui discernimento completo, que precisa ser ensinado, ser moldado, ser educado. Conforme, aduz o Dicionário Aurélio, por exemplo, a criança é ser humano de tenra idade. Da mesma forma, o dicionário, ainda define, como um tempo de crescimento, no ser humano, que se pode ser visualizado desde o nascimento até a puberdade. (Moraes, 2005, p. 57).

Outra fase de extrema importância na vida do ser humano é a fase da adolescência/juventude, sendo uma fase da vida que faz jus a uma atenção especial, uma vez que se trata de período de passagem no liame entre a infância e a maioridade, já sendo adulto esta transição, a depender de sua condução, pode trazer perturbações futuras, podendo prejudicar o desenvolvimento do indivíduo. (Paschoal \& Marta, 2012, p. 228).

$\mathrm{O}$ período da fase da infância é muito tênue, se na vida de uma criança de 0 a 12 anos incompleto, é uma fase totalmente dependente dos adultos e dos seus representantes legais, seja por circunstância ou por afetividade, pois a criança não tem forças e nem condições própria para poder entrar com ação, e dependem da representação de seus pais ou tutores em 
defesa de seus direitos, assim como na fase da adolescência que compreende dos 12 anos completos aos 18 anos de idade incompletos, pois estes possuem personalidade jurídica própria, mas deverão ser assistidos por seus responsáveis na prática de qualquer ato sendo sujeito de direitos como qualquer outro cidadão. Assim, fez-se necessário a criação de leis específicas para proteger e garantir os direitos da criança e do adolescente através da Carta Magna Brasileira, promulgada em 1988, e com ela a lei de garantia proteção, ECA, dando segurança jurídica aos operadores e os beneficiários direto da lei que são as crianças e os adolescentes.

Segundo Saut (2007, p. 65), na época da constituinte de 1986, trouxe a obrigatoriedade da presença de um advogado para os procedimentos processuais, que envolve criança e adolescentes com garantia ao contraditório, igualdade processual, ciências e conhecimento do ato infracional praticado, e a garantia de constituir defesa técnica profissionalizada (art. $227, \S 3^{\circ}$, CF), (Brasil, 2004).

Atualmente, a criança e o adolescente possui direito à prestação jurisdicional, tendo acesso a todas às questões relacionadas à sua internação pelo sistema infracional, semiliberdade, às testemunhas, informações dos profissionais que atenderam, direito ao recurso, direito de ser acompanhado por profissional habilitado, se necessário, usufruir da justiça gratuita tendo em vista sua situação socioeconômica, através da Defensoria Pública, e, na falta, deste, será designado Defensor Jurídico garantido por Programa do Conselho dos Direitos garantido pelo Fundo Institucional da Criança e do Adolescente. (Saut, 2007, p. 65).

A busca pela segurança social e políticas públicas em prol da criança e do adolescente, é tema bastante atual e latente na sociedade do terceiro milênio, pois a violência bate às nossas portas e deve-se buscar na política e na assistência social meios para se garantir segurança social, e fazer com que as crianças e os adolescentes sintam-se protegidos e acalentados com atenções governamentais. Um governo impor a felicidade do povo em um Estado Democrático de Direito, direcionando um dispositivo que apenas proteja aos mais miseráveis, como crianças e mulheres, dá a certeza de que o governo está fazendo uma correlação imediata com a política do pão e circo dos líderes romanos. (Sposati, 2017).

São tantos os questionamentos que perturbam a mente humana, como liberdade, amor, vida e morte, bem e mal, que é difícil acreditar que o Estado possa definir o que é uma criança feliz e se achar capaz e fazedor dessa felicidade por meio de visitas, é tão insipiente e sem noção, que chega a ser hilário. Dispor em um mesmo patamar proteção social e felicidade como atribuições estatais, é acima de tudo enclausurar as liberdades dos indivíduos. (Sposati, 2017).

Demonstra-se claramente, que o Programa da Criança Feliz traz um retrocesso na gama de institutos legais que protegem as crianças, à chamada cultura do primeiro damismo, bem como uma afronta a princípios constitucionais e legais, sendo evidenciado que tem levado a uma atitude estatal de desobrigação do dever de proteção que o Estado deveria fazer frente às políticas públicas essenciais para uma vida digna. O PCF está na contramão do princípio da universalidade assegurado pela Convenção sobre os Direitos da Criança, pela CF/1988, pelo ECA e demais normas correlatas. Não se respeitando nem mesmo o atendimento às crianças de família em situação de vulnerabilidade, com afronta latente ao princípio da universalidade (Sposati, 2017).

Nota-se que há um grande problema a ser resolvido quanto à questão da segurança para as crianças e os adolescentes poderem ter a chance de ter uma vida mais tranquila, felizes e serem educados de forma harmoniosa, tanto dentro dos seus lares como sendo parte efetiva da comunidade, que com tanta dificuldade foi adquirindo esses direitos e que compõem o nosso atual ordenamento jurídico. O Estado tem um problema crônico no seio da comunidade para resolver, tanto no que tange a questão da violência dentro das famílias, e que acaba por caracterizar violência doméstica, assim como na questão da educação social, pois só assim teremos uma sociedade mais segura e confiável.

Os direitos fundamentais, de acordo com Canotilho (apud Moraes, 2015), possuem duas faces: a de liberdade negativa - em que é proibido ao Estado a intromissão na esfera jurídica do indivíduo; e a de liberdade positiva - em que cabe aos 
indivíduos o direito de exigir do Poder Público uma ação, um fazer, ou seja, a realização prática de direitos, bem como buscar solucionar as omissões jurídicas. Leal (2013, p. 206) afirma ainda que a felicidade está contida no rol dos direitos fundamentais, pois "simbolizam aspirações de igualdade, liberdade e segurança".

É notável, que legítima as escolhas ou anseios que não venham a ferir a dignidade da pessoa humana - nem venha a denegrir a proteção jurídica de outros cidadãos. Tendo, então o desdobramento da participação estatal em duas modalidades, na qual na primeira modalidade o Estado não pode intervir nas metas pessoais e opções legítimas de cada indivíduo; na outra modalidade, o cidadão tem o livre arbítrio para decidir e escolher sobre as questões de sua vida, de forma legal. (Leal, 2013, p. 206).

O correto é que todo atendimento sob a responsabilidade da Segurança Pública deve estar em consonância com o Poder Judiciário, o Ministério Público, a Defensoria Pública e a Assistência Social. A segurança pública compõe um conjunto de garantias que são prestadas com responsabilidade social e estatal dando uma atenção especial à criança e ao adolescente que são autores de atos infracionais, tendo também a segurança pública papel importante no tocante a prevenção e o controle social, respeitando os postulados legais compostos no ECA, à vista de seus princípios e normas no que dizem respeito à inimputabilidade do menor. A criança e o adolescente tem direito de ser acompanhado por advogado, bem como ter atendimento com profissionais de diversas áreas, no sentido de garantir o interesse da criança e do adolescente, a sua dignidade humana, com direito à proteção total, tendo preferência absoluta, desde que esteja em situação de vulnerabilidade em decorrência de ser criança ou adolescente, devendo à Segurança Pública reprimir à violência, dando um atendimento igualitário a todos, com uma rede bem coordenada e com ações combinadas em todos os níveis (art. 88, inciso V do ECA). (Brasil, 2003).

Existe, no Brasil, uma realidade bastante nítida e diferenciada entre adolescentes, a depender da classe social em que se desenvolveram, em que nas classes menos privilegiadas, que representam aproximadamente 70 milhões de adolescentes com menos de 18 anos de idade, as oportunidades são mais escassas, tendo o jovem a possibilidade de viver várias experiências, e muitas as vezes tendo que suprimir outras experiências por conta de sua realidade social que, às vezes, não permite a esse jovem somente se dedicar aos estudos nesta fase da vida, sendo esta fase abortada, ou seja, considerado apenas um período que anterior a constituição da sua família. Já nas classes econômicas mais privilegiadas, o jovem está mais solto e vive esta fase de forma mais leve e intensa, com todo o período de experimentação sem muitos problemas emocionais, econômicos e sociais; não assume responsabilidades, já que apenas dedica-se aos estudos, sendo essa a sua via de transposição para mundo adulto. A adolescência, no Brasil, portanto, possui diferentes configurações, como abordado acima, sendo que essa particularização depende da classe social em que o adolescente está inserido. Atualmente, é comum associar a adolescência com drogas, educação, sexo, impasses com o estabelecimento de limites, violência, e formas inadequadas de conduta, etc. (Paschoal \& Marta, 2012, p. 229).

Para se fazer uma análise criteriosa da fase adolescente, é muito importante levar em conta os aspectos psicológicos, cognitivos, socioculturais e etc. Ademais, tem que se levar em consideração o contexto em que esse jovem está inserido. É importante notar que as particularidades físicas e biológicas são consideradas "marcas" presentes em todo adolescente, como forma de demonstração de transição entre a vida infantil e a adulta, o que não se pode afirmar é que a determinação da fase adolescente seja definitiva e unicamente reconhecida através da idade e por conta das alterações orgânicas. (Paschoal \& Marta, 2012, p. 230).

No Brasil, desde a era colonial, sempre existiu a classe economicamente menos favorecida. E com as crianças e os adolescentes inseridos em famílias carentes, até hoje, esse problema no Brasil vem se arrastando, e quem mais sofre com essa vulnerabilidade são eles, pois não têm a quem recorrer e suprir de fato as suas reais necessidades. É imprescindível um olhar estatal para essas crianças que vivem à margem da sociedade para que estas possam ter seus direitos garantidos de forma 
igualitária e justa, para que possam se tornar adultos de caráter, de muito senso crítico e colaborativos para o sucesso e a implementação de políticas de desenvolvimento e acolhimento deste grupo tão vulnerável.

É muito importante destacar que a educação infantil tem como encargo complementar a educação do indivíduo e não visa substituir o papel da família, como muitos pensam. A escola é um elo de ligação com a família e com a sociedade para que unidas possam ofertar o que a criança realmente precisa para seu desenvolvimento sadio e para sua verdadeira felicidade. Tanto a família como a escola possuem o papel fundamental no desenvolvimento da criança, com fins à proteção da mesma de forma insubstituível. (Ferreira \& Garms, 2009, p.554).

O cuidado infantil deixa de ser apenas atribuição da família, dando ênfase como essencial dispositivo social no crescimento do desenvolvimento humano, a ser observado pelas autoridades públicas. Nessa mesma dinâmica, encontra-se presente a ideia de que cuidado e socialização da criança pequena são responsabilidades a serem divididas entre família e Poder Público. Levando-se em conta o cenário histórico, em que pode ocorrer alteração de rumos das funções socializadoras do espaço doméstico a um campo mais amplo e socializado. (Ferreira \& Garms, 2009, p.554).

Para Luiz Alberto David Araújo (2000, p.74), a própria ideia de vida em sociedade leva a apreensão de que esse convívio coletivo só foi aceito pelas pessoas por crer que a vida em sociedade, tem seus ônus e suas benesses, proporcionando maiores condições de obter a felicidade do que se viver em mundo de forma isolada.

Acredita-se de forma convicta que a felicidade é um direito fundamental, pois com ela o indivíduo está sendo acobertado e respeitando outros princípios constitucionais, tendo como princípio base o da dignidade da pessoa humana. Dessa forma, cabe ao Estado o dever de agir de forma eficaz para a realização e aplicação de todas as normas constitucionais que protegem os direitos das pessoas, para que possa proporcionar a estas condições de torná-las e mantê-las felizes, no seu cotidiano, sem ofender à sua dignidade. (Paschoal \& Marta, 2012, p. 231).

Com a reestruturação da família brasileira, hoje em dia, mais que nunca, faz-se necessário mais investimento de políticas públicas em todo o cenário nacional e atingir as metas que o Brasil fez muitos acordos e se comprometeu em cumprir diante as instituições internacionais com a erradicação da pobreza e do analfabetismo, assim vem se protelando e não alcançando o objetivo maior para poder resolver o problema da comunidade mais pobre do País, afetando diretamente a estimativa dos nossos jovens de 0 a 18 anos, que sofrem e o Brasil de hoje é o Brasil de amanhã.

Importante ressaltar que a felicidade ainda não é garantia constitucional, mas está intimamente atrelada ao Princípio Maior, que é o Princípio da Dignidade da Pessoa Humana, é uma virtude e um direito a ser conquistado, que se destaca e que a felicidade deve ser atributo que deve estar inserido no contexto social de todo ser vivo, trata-se de uma forma de viver com dignidade, sendo, portanto, um direito das crianças e dos adolescentes.

É notório, através do Recurso Extraordinário no $477.554 / \mathrm{MG}$, a preocupação até mesmo na corte suprema, o direito à busca da felicidade, asseverando, em vários momentos, ser a felicidade "como expressão de uma ideia-força que se origina do princípio da essencial dignidade da pessoa humana verdadeiro pedido constitucional implícito". E, até mesmo, constando no rol de princípios fundamentais. (Brasil, 2011).

A relação entre educação infantil e a família tem por objetivo uma ação socializadora e educacional da criança, e postula uma estreita relação entre pais e escola, não se limitando apenas a um convívio formal (como reunião de pais) e conhecimento, devendo-se retirar desta relação os seus maiores benefícios para a crianças e adolescentes. Família e escola infantil devem trabalhar em conjunto, em atuações educacionais e socializadoras, em síntese, devem possuir objetivos comuns, sendo que cada segmento deve expender esforços para realização de ações dentro de suas especificidades, instituição de educação infantil é instituição, e família é família, tendo a criança como o elo prioritário de direitos dessa união. (Ferreira \& Garms, 2009, p.555).

A família deve reconhecer a importância da educação infantil como ação socializadora de forma unida com os pais. 
Ter a consciência de que seus filhos não são apenas clientes, mas devem estabelecer uma parceria com a escola, pois são os primeiros, principais e permanentes educadores de suas crianças e, dessa forma, aos pais compete à responsável missão de criar seus filhos, o que atualmente tem se notado por parte de alguns pais o desejo da inversão desse papel, devendo essa ideia ser exterminada em busca do resgate que a educação vem de casa em primeiro lugar. (Sambrano, 2006, p.153).

Segundo Paschoal e Marta (2012), aduzem que é importante, frisar que o direito à coabitação familiar é um direito constitucional, sendo que as crianças e os adolescentes não podem ser tolhidas do direito de usufruir de um direito fundamental por preconceito, o que fere totalmente o Princípio da Dignidade da Pessoa Humana previsto no inc. III, art. $1^{\circ}$, que é mola mestra de nossa Carta Magna de 1988. (Brasil, 1998).

A ideia é de que em toda família o amor é disseminado dia a dia, no diálogo, na confiança, na verdade e no afeto, são esses atributos que dão corpo aos laços familiares, fortificando-os cada vez mais. $\mathrm{O}$ amor deve estar presente tanto em famílias daqueles que nasceram e permaneceram com suas mães de sangue, como também para aqueles que foram buscados como filhos de coração. A estrutura da família, com o desenvolvimento e o êxito dos seus componentes, não está atrelada à genética ou pela escolha de família substituta. (Paschoal \& Marta, 2012, p. 233).

O mínimo existencial que o Estado assegurará está inserida à segurança. Contudo, não deverá assegurar meios para que o ser humano usufrua de próprio planejamento e execução de seus desejos. O Estado poderá garantir ao indivíduo o início da busca pela sua felicidade.

Leal (2013, p. 213) continua afirmando que o direito à felicidade é mais importante que o direito de suprir às necessidades básicas do cidadão.

Em síntese, hoje devemos asseverar que o Brasil passa por situação de utopia, pois vivemos um sonho não realizado, mas que desejamos um dia alcançar e que passa gerações e gerações, e o Brasil sempre está na corda bamba, como é sabido, no entanto, essa busca constante de um dia ver nossas crianças e adolescentes realizarem os seus sonhos devemos sempre apoiar e motivá-los para manterem a esperança acesa e a nossa comunidade em união, porque pelo menos teremos uma sociedade que luta por seus ideais.

A construção social do destino escolar e da ocupação no mercado de trabalho de cada indivíduo, como o histórico de repetências na escola e a falta de emprego, são fatores de socialização que contribuem para as desigualdades sociais. Essa realidade produz efeitos diretos e inevitáveis sobre os rumos escolares e profissionais de cada indivíduo. (Ferreira \& Garms, 2009, p.550).

Expor sobre o direito à felicidade, bem como sua proliferação, à primeira vista pode ser considerada uma tarefa complexa. Todavia, a evolução pessoal e intelectual que se proporciona ao ser analisada a felicidade dentro de uma perspectiva jurídica é de grande valor, uma vez que ser feliz constitui um desejo básico que todo indivíduo levando em consideração ao exercer seus atos e realização de seus desejos legítimos. Ou seja, a felicidade é um sentimento que extrapola a mera existência material. (Souza, Ramos \& Cordeiro, 2018, p.132).

\section{Considerações Finais}

Feito a análise da perspectiva de direito à felicidade da criança e do adolescente, foi confirmada a necessidade de dar uma atenção especial à formação desses sujeitos e verificados os direitos garantidos e sem precisar constrangê-las, dando-se assim aplicabilidade ao Princípio da Dignidade da Pessoa Humana.

O problema desse artigo em tela muito debatido, afirmado e muito bem explanado foi: O que caracteriza e como se fundamenta juridicamente o direito à felicidade de criança e do adolescente? Para que toda criança e adolescente tem o direito de ser feliz, e esta felicidade deve ser alçada e alcançada por meio da contribuição de todos e por todos, a partir do Poder Público através de seu poder de tutela dos direitos das crianças e adolescentes. Acreditou-se que chegaríamos a seguinte 
hipótese: Afirmamos que tanto a criança como o adolescente juridicamente são sujeitos passíveis de direitos e deveres, resguardado o direito fundamental à felicidade sendo esses direitos fundamentados juridicamente garantidos na CF/1988, e no ECA, tendo o Estado papel preponderante, assim como a sociedade em geral, o dever de expender medidas de proteção e auxílio, sendo essenciais que se desenvolvam em uma família que as ame, ampare, proteja ensinando quais são seus deveres, direitos, regras e limites. Sem nenhuma discriminação, preconceito, dando-se assim aplicabilidade ao Princípio da Dignidade da Pessoa Humana para que possa almejar e posteriormente alcançar e adquirir a felicidade plena.

Demonstramos com o objetivo geral que fazer uma análise do direito à felicidade da criança e do adolescente em contrapartida de políticas governamentais e da parcela de contribuição da sociedade, quanto a fatores e situações de riscos, em que há a vulnerabilidade que compromete a felicidade das crianças e dos adolescentes, como seres que fazem parte da sociedade, que merecem atenção especial e serem valorizados, educados com princípios sem discriminação e terem seus direitos preservados, respeitados, e sempre ampliados de forma à dar proteção total, com todo amparo legal.

Este trabalho teve como objetivo específico demonstrar que os direitos das crianças estão sendo violados e feridos por falta de políticas públicas, por falta de um olhar mais humanitário, respeitoso, por parte dos entes públicos, também como observamos que os aspectos e as atitudes positivas que podem trazer a felicidade das crianças, transformando em atitudes simples e verdadeiro engajamento, tanto do Poder Público como de toda a sociedade, mostrando caminhos a serem seguidos e tentou-se mostrar onde reside a verdadeira felicidade das crianças, que no futuro se tornarão adultos responsáveis, os quais, com certeza trará em seu mais profundo íntimo a vontade de proporcionar a felicidade a esses seres tão vulneráveis.

Adentrou-se no prisma da justificativa desse artigo a contribuição para a formação e desenvolvimento do tema ligado a infância e de toda a área profissional como juristas, operadores do Direito, conselheiros tutelares, educadores. Foi pensando na contribuição para a ciência jurídica no direito à criança e ao adolescente que esta pesquisa grande relevância foi levantada. Buscou-se a necessidade de trazer para toda a sociedade, alertando a todos para que se interessem mais pelos direitos dos pequenos, pois eles não têm personalidade jurídica própria, nem forças e nem condições de reagir, devendo ser protegidos e assistidos por adultos que compõe a sociedade e possuem essa designação. É a tamanha competência de acordo com cada uma.

Resultou-se desse estudo teórico a necessidade de dar mais apoio e amparo legal para realização da felicidade das crianças e dos adolescentes no que tange a proteção integral dos direitos da infância, nesse intuito dedicou-se e se debruçou intensamente na busca de melhor qualidade de estudo em que foi possível a coleta dados e feita a extração da essência dos artigos científicos e livros, que deram embasamento ao trabalho de pesquisa, concluímos que com os artigos e material de estudo levantado, bem como a utilização da legislação e jurisprudência correlata, explicitou-se que toda criança e todo adolescente tem o direito absoluto de ser feliz, pois enquanto a criança estiver felicidade de verdade, ela terá uma grande possibilidade de ter uma juventude mais feliz e por conseguinte se tornará uma pessoa adulta mais feliz.

Como sugestões a trabalhos futuros trazemos a importância do aprofundamento desta temática tão relevante quanto necessária. $\mathrm{O}$ direito à felicidade da criança e do adolescente precisa ser irrestrito, por ser essencial. Como se discutiu neste artigo, o conceito de felicidade abarca outros conceitos, direitos e necessidades muito importantes de serem garantidos.

\section{Referências}

Alarcón P. J. L. (2004). Patrimônio genético humano e sua proteção na Constituição Federal de 1988. São Paulo: Método.

Araujo L. A. D. (2000). A proteção constitucional do transexual. São Paulo: Saraiva.

Aristóteles. (2003). Ética a Nicômaco. Tradução: Pietro Nassetti. São Paulo: Martin Claret.

Brasil. (1998). Constituição da República Federativa do Brasil $1998 . \quad$ Brasília, $1988 . \quad$ Link: <http://www.planalto.gov.br/ccivil_03/constituicao/constituicaocompilado.htm>.

Brasil. (2004). Constituição da República Federativa do Brasil. 33. ed. atual. e ampl. São Paulo: Saraiva. 
Brasil. (1990). Decreto n. 99.710, de 21 de novembro. Convenção sobre os Direitos da Criança. Brasília: Diário Oficial da União.

Brasil. (2003). Estatuto da criança e do adolescente. Brasília: Câmara dos Deputados.

Brasil. (1990). Lei $\mathrm{n}^{\circ}$ 8.069, de 13 de julho. Estatuto da Criança e do Adolescente. Brasília: Diário Oficial da União. Link: <http://www.planalto.gov.br/ccivil_03/leis/18069.htm>.

Brasil. (1993). Lei nº 8.742, de 7 de dezembro. Lei Orgânica da Assistência Social. Brasília: Diário Oficial da União.

Brasil. (2010). Senado Federal. Proposta de Emenda à Constituição $n^{o} 19$, de 7 de julho. Altera o artigo $6^{\circ}$ da Constituição Federal para incluir o direito à busca da Felicidade por cada indivíduo e pela sociedade, mediante a dotação pelo Estado e pela própria sociedade das adequadas condições de exercício desse direito. Brasília. Link: <http://www.senado.gov.br/atividade/materia/getTexto.asp?t=80759>.

Brasil. (2011). Supremo Tribunal Federal. Recurso Extraordinário $n^{o}$ 477.554/MG. Relator: Min. Celso de Mello. Brasília. Link: <http://stf.jus.br/portal/processo/verProcessoTexto.asp?id=3020473\&tipoApp=RTF>.

Ferreira A. H. (2010). Dicionário da língua portuguesa. 5. ed. Curitiba: Positivo, p.2222.

Ferreira L. A. M. \& Garms G. M. Z. (2009). Educação infantil e a família: perspectiva jurídica desta relação na garantia do direito à educação. RBPAE, 25 (3), p. 545-561.

Figueiredo M. F. (2007). Direito Fundamental a saúde: Parâmetros para sua eficácia e efetividade. Porto Alegre: Livraria do Advogado.

Gilbert D. (2006). Stumbling on happiness. New York: Alfred A. Knopf.

Girade H.A. \& Didonet V. (Coord.). (2005). O município e a criança de até 6 anos: direitos cumpridos, respeitados e protegidos. Brasília: Unicef.

Gomes M. R. C. S. (2008). Nacionalização da política de assistência social e governos estaduais no Brasil: o caso do estado de São Paulo. São Paulo, 329 p. Tese (Doutorado em Serviço Social) - Programa de Pós-Graduação em Serviço Social, PUC, São Paulo. Link: <https://tede2.pucsp.br/handle/handle/17897\#preview-link0>.

Gonçalves J. R. (2020). Como elaborar uma resenha de um artigo acadêmico ou científico. Revista JRG de Estudos Acadêmicos. 3 (7), jul.-dez., p.95-107.

Gonçalves J. R. (2019). Como escrever um Artigo de Revisão de Literatura. Revista JRG de Estudos Acadêmicos, 2 (5), p. $29-55$.

Gonçalves J. R. (2019). Como fazer um Projeto de Pesquisa de um Artigo de Revisão de Literatura. Revista JRG de Estudos Acadêmicos, 2 (5), p. 02-28.

Gonçalves J. R. (2019). Manual de artigo de revisão de literatura. Brasília: Instituto Processus, Coleção Trabalho de Curso, 2 (5).

Kaloustian M. (Org.). (2000). Família Brasileira: A base de tudo. 5. ed. São Paulo: Cortez.

Kimmel D. C. \& Weiner I. B. (1995). Adolescence: A developmental transition. New York: Willy \& Sons.

Lamy M. (2007). Conceitos indeterminados: limites jurídicos de densificação e controle. Revista Internacional d’Humanitats. São Paulo, 10 (11), p. 53-58.

Leal S.T. (2013). Direito à felicidade: história, teoria, positivação e jurisdição. São Paulo, 357 p. Tese (Doutorado em Direito Constitucional) - Programa de Pós Graduação em Direito Constitucional, Pontifícia Universidade Católica de São Paulo. Link: <https://sapientia.pucsp.br/bitstream/handle/6202/1/Saul\%20Tourinho\%20Leal.pdf>.

Machado M.T. (2003). A proteção constitucional das crianças e do adolescente e os direitos humanos. Barueri: Manole.

Moraes A. (2015). Direito constitucional.31. ed. São Paulo: Atlas.

Moraes A. A. (2005). Educação Infantil: uma análise das concepções de criança e de sua educação na proteção acadêmica recente. Florianópolis, 205 p. Dissertação (Mestrado em Educação) - Programa de Pós-Graduação em Educação, Universidade de Santa Catarina. Link: <https://core.ac.uk/download/pdf/30368182.pdf>.

Paschoal, G. R. \& Marta T. N. (2012). O papel da família na formação social de crianças e adolescentes. Confluências, PPGSD-UFF, Niterói, 12 (1), páginas 219 a 239, ISSN 1678-7145.

Postman N. (1999). O Desaparecimento da Infância. Rio de Janeiro: Graphia.

Salazar A. (2008). As transformações do papel social da família. Revista MPD Dialógico, 5 (20).

Sambrano T. M. (2006). Relação instituição de educação infantil e família. In: ANGOTTI, Maristela (Org.). Educação Infantil: para que, para quem e por quê? Campinas: Editora Alínea.

Saut R. D. (2007). O direito da criança e do adolescente e sua proteção pela rede de garantias. Revista Jurídica - CCJ FURB, 11 (21), p. $45-73$.

Sêda E. (1992). O estatuto da criança e do adolescente e a participação da sociedade. In: PEREIRA, Tânica da Silva (Coord.). Estatuto da criança e do adolescente: estados sociojurídicos. Rio de Janeiro: Renovar.

Silveira J. C. (2000). Infância na Mídia: sujeito, discurso, poderes. Porto Alegre: FACED/UFRGS.

Sosnowski A. (2013). A felicidade, segundo o filósofo Mário Sergio Cortella. Exame. Link: <https://exame.abril.com.br/carreira/felicidade-carreira-emaratona/>. 
Research, Society and Development, v. 10, n. 5, e44510515251, 2021

(CC BY 4.0) | ISSN 2525-3409 | DOI: http://dx.doi.org/10.33448/rsd-v10i5.15251

Souza E. A. R, Ramos Z. M. X \& Cordeiro C. V.V. (2018). Direito à felicidade: análise principiológica e desdobramentos no ordenamento jurídico brasileiro. Revista do Direito Público. Londrina, 13 (2), p.100-137.

Sposati A. (2017). Transitoriedade da felicidade da criança brasileira. Serviço Social e Sociedade, São Paulo, nº. 130. Link: <http://dx.doi.org/10.1590/01016628.122>

Tiburi M. A. (2007). A felicidade é coletiva. Revista Vida Simples. São Paulo, p. 50-51. 